Article

\title{
Antimigration Effects of the Number of Flaps on a Plastic Stent: Three-Dimensionally Printed Pancreatic Phantom and Ex Vivo Studies
}

\author{
Dae-Sung Ryu ${ }^{1,+}$, Joon-Myeong Choi ${ }^{2,+}{ }^{(\mathbb{D}}$, Woo-Jin Kim ${ }^{3}$, Jeon-Min Kang ${ }^{1}$, Ki-Baek Lee ${ }^{1}$, Yu-Been Park ${ }^{1}$, \\ Dong-Sung Won ${ }^{1}$, Ji-Won Kim ${ }^{1}$, Song-Hee Kim ${ }^{1}$, Pyeong-Hwa Kim ${ }^{4}$, Song-Cheol Kim ${ }^{5,6, *, \ddagger}$ (D) \\ and Jung-Hoon Park $1, *, \ddagger \mathbb{D}$
}

1 Biomedical Engineering Research Center, Asan Institute for Life Sciences, Asan Medical Center, 88 Olympic-ro 43-gil, Songpa-gu, Seoul 05505, Korea; kryuds@amc.seoul.kr (D.-S.R.); miny2208@amc.seoul.kr (J.-M.K.); beall34@amc.seoul.kr (K.-B.L.); ybeen9733@amc.seoul.kr (Y.-B.P.); ehdtjd3004@amc.seoul.kr (D.-S.W.); kimjw203@amc.seoul.kr (J.-W.K.); zxcuiop55@amc.seoul.kr (S.-H.K.)

2 Department of Convergence Medicine, University of Ulsan College of Medicine, 88 Olympic-ro 43-gil, Songpa-gu, Seoul 05505, Korea; jm5901@snu.ac.kr

3 Safety System R\&D Group, Korea Institute of Industrial Technology, 320 Techno-sunhwan-ro, Yuga-myeon, Dalseong-gun, Daegu 42994, Korea; woojinkim@kitech.re.kr

4 Department of Radiology, Asan Medical Center, University of Ulsan College of Medicine, 88 Olympic-ro 43-gil, Songpa-gu, Seoul 05505, Korea; phkim@amc.seoul.kr

5 Division of Hepatobiliary Pancreas Surgery, Department of Surgery, Asan Medical Center, University of Ulsan College of Medicine, 88 Olympic-ro 43-gil, Songpa-gu, Seoul 05505, Korea

check for updates

Citation: Ryu, D.-S.; Choi, J.-M.; Kim, W.-J.; Kang, J.-M.; Lee, K.-B.; Park, Y.-B.; Won, D.-S.; Kim, J.-W.; Kim, S.-H.; Kim, P.-H.; et al. Antimigration Effects of the Number of Flaps on a Plastic Stent: Three-Dimensionally Printed Pancreatic Phantom and Ex Vivo Studies. Appl. Sci. 2021, 11, 4830. https://doi.org/10.3390/app11114830

Academic Editor: Rossella Bedini

Received: 29 March 2021

Accepted: 18 May 2021

Published: 25 May 2021

Publisher's Note: MDPI stays neutral with regard to jurisdictional claims in published maps and institutional affiliations.
6 Asan Medical Institute of Convergence Science and Technology (AMIST), Asan Medical Center, University of Ulsan College of Medicine, 88 Olympic-ro 43-gil, Songpa-gu, Seoul 05505, Korea

* Correspondence: drksc@amc.seoul.kr (S.-C.K.); jhparkz@amc.seoul.kr (J.-H.P.)

+ D.-S.R. and J.-M.C. contributed equally to this work and are the co-first authors.

$\ddagger$ S.-C.K. and J.-H.P. contributed equally to this work and are the co-corresponding authors.

\begin{abstract}
Stent migration is a significant obstacle to successful stent placement. There has been no investigation of the effect and quantitative interpretation of flaps attached to a plastic stent (PS) on antimigration. The antimigration effects of the number of flaps on a PS in a 3D-printed pancreatic phantom (3DP) and extracted porcine pancreas (EPP) were investigated. Four PS types were used in this study: stent without flaps (type 1), stent with two flaps (type 2), stent with four horizontally made flaps (type 3), and stent with four vertically made flaps (type 4). The stents were measured and compared for antimigration force (AMF) in the 3DP and EPP using a customized measuring method and an integrated measuring device. The mean maximum AMFs (MAMFs) in types 2, 3, and 4 were significantly higher than that in type 1 (all $p<0.001$ ). Moreover, the mean MAMFs in types 3 and 4 were significantly higher than that in type 2 (all $p<0.001$ ). When the flaps were removed from the pancreatic duct, the AMF decreased rapidly. As the number of flaps increased, the antimigration effects significantly increased in the 3DP and EPP. However, the direction of the flaps did not affect the MAMF. The position of the flaps attached to the surface of the stent affected the AMF.
\end{abstract}

Keywords: plastic stent; stent migration; 3D-printed phantom; pancreas; pancreatic duct; porcine pancreas

\section{Introduction}

Endoscopic placement of a plastic stent (PS) is currently a well-accepted therapeutic option for pancreatic duct (p-duct) strictures caused by chronic or acute pancreatitis, traumatic injuries, surgical complications, pseudocysts, and malignant diseases of the pancreatic head and periampullary regions [1-7]. Furthermore, the placement of a transanastomotic stent using various stent materials is commonly used to prevent anastomotic leakage and subsequent fistula and stricture formation at a pancreatoenteric anastomosis. 
However, various stent-related complications, such as infection, stent obstruction, duodenal erosions, ductal perforation, and either proximal or distal migrations, have been reported in clinical trials [8]. Especially regarding stent migration, distal migration was rarely harmful as the migrated stent passes into the duodenum and is usually excreted. However, proximal migration further into the p-duct has been shown to occur at a rate of 5-6\% and results in severe pancreatitis [9]. Stent migration is one of the significant obstacles for successful stent placement. Migrated stents pose a serious management dilemma, with some patients requiring surgical removal of the stents [10].

Most PSs in studies have been straight or sigmoid-shaped with barbs or flaps at each end to prevent migration or dislocation [11]. However, design and quantitative studies are insufficient to determine whether the number or direction of flaps or barbs prevents stent migration in the p-duct. In previous studies, there was no investigation of the effect and quantitative interpretation of flaps attached to the PS on antimigration. Therefore, four PS types, having different numbers and directions of flaps, were manufactured. Furthermore, the artificial 3D-printed pancreatic phantom with p-duct (3DP) and extracted porcine pancreas (EPP) were developed to evaluate the antimigration effects of a PS. This study investigates the antimigration effects of the number of flaps in a PS on 3DP with p-duct and EPP.

\section{Materials and Methods}

\subsection{Preparation of the PSs}

The PSs used in this study were designed and manufactured using a biocompatible polymer by a micro-extrusion process. We used polyether block amide Pebax 5533 SA MED polymer (Arkema, France), which is a representative biocompatible elastomer actively used in various polymer stents and catheters. The mechanical properties of Pebax5533 are presented in Table 1. In addition, the polymer was compounded with $20 \mathrm{wt} \% \mathrm{BaSO}_{4}$ to provide radiopacity.

Table 1. Intensive and mechanical properties of Pebax5533 SA01 MED $+20 \mathrm{wt} \% \mathrm{BaSO}_{4}$.

\begin{tabular}{cc}
\hline Properties & Values (Unit) \\
\hline Density & $1010\left(\mathrm{~kg} / \mathrm{m}^{3}\right)$ \\
Melting point & $159\left({ }^{\circ} \mathrm{C}\right)$ \\
Flexural modulus & $170(\mathrm{MPa})$ \\
Tensile strength & $12(\mathrm{MPa})$ \\
Melt flow index (MFR) & $7(\mathrm{~g} / 10 \mathrm{~min})$ \\
\hline
\end{tabular}

The stents were made according to our specifications (KITECH; Korea Institute of Industrial Technology, Daegu, Korea) and are not commercially available elsewhere. The stents had a tubular structure with or without flaps and were $2 \mathrm{~mm}$ in diameter and $30 \mathrm{~mm}$ in length. Each flap was $2 \mathrm{~mm}$ in length and projected $60^{\circ}$ toward the papilla.

As shown in Figure 1, the flexural stress of the dried stent shaft was measured according to the vertical displacement at room temperature. A three-point bending test method was applied, and the speed at which the clamp presses the load point was set to $20 \mathrm{~mm} / \mathrm{min}$. The maximum stress of the PS shaft was analyzed to be $0.56 \mathrm{MPa}$.

To analyze the effect of the number and direction of flaps on antimigration, four types of PS were prepared as follows: stent without flaps (type 1) as a control, stent with two flaps (type 2) as a commonly used example, stent with four horizontally made flaps (type 3 ) attached in the same direction as type 2, and stent with two horizontally and two vertically made flaps (type 4 ) attached with a $90^{\circ}$ difference (Figure 2a). 


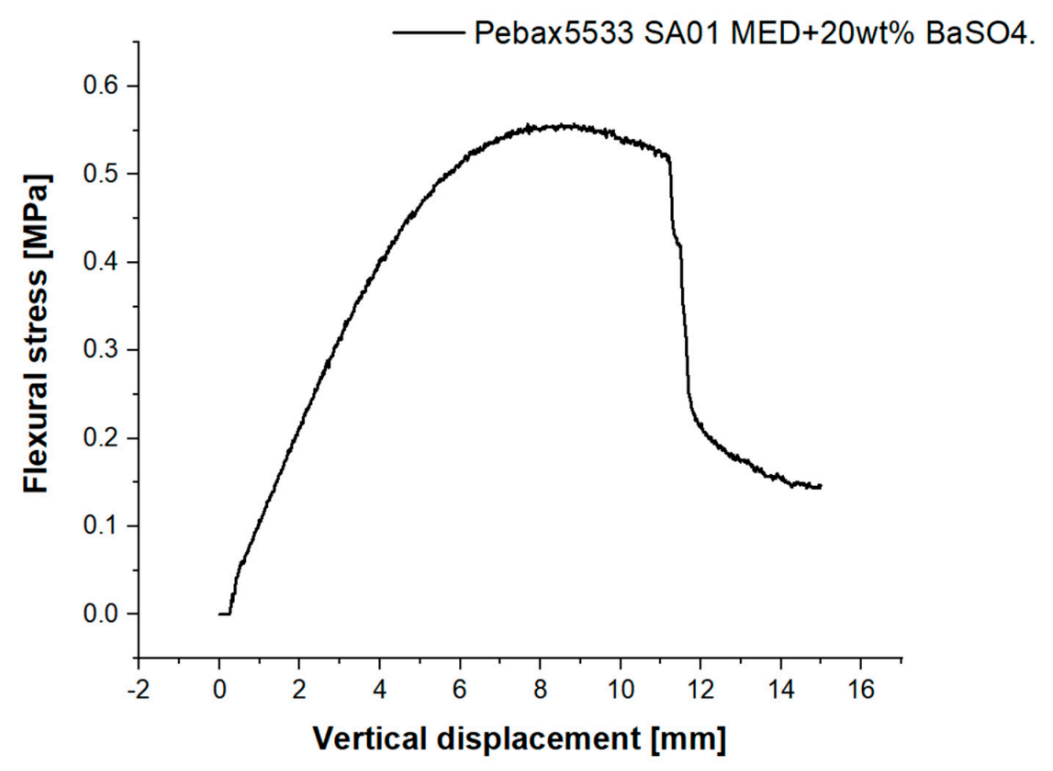

Figure 1. Flexural stress of the plastic stent shaft according to the vertical displacement.

(a)

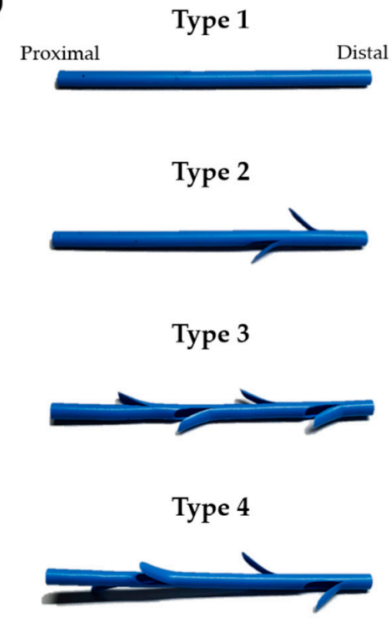

(b)

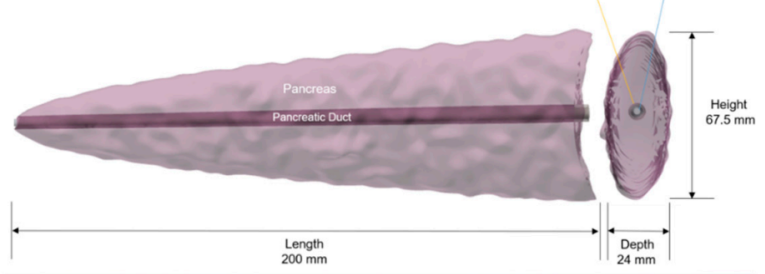

(c)

$100110 \quad 120 \quad 1800$

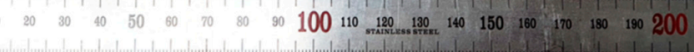

Figure 2. Types of plastic stents (PSs) with or without flaps and 3D-printed pancreatic phantom with the pancreatic duct (3DP) model. (a) The tubular structure with or without flaps was $2 \mathrm{~mm}$ in diameter and $30 \mathrm{~mm}$ in length. Each flap was $2 \mathrm{~mm}$ in length and projected $60^{\circ}$ toward the papilla. (b) Photographs of modeling and specification. (c) Photographs of a 3DP model.

\subsection{Design of the 3DP}

The 3DP, similar to a human pancreas from an open-source standard triangulated language file, was developed using injection molding of liquid silicone rubber. The modeling of the pancreas with moldings and the 3DP were designed and made by local manufacturers (ANYMEDI, Seoul, Korea). The 3DP consisted of the pancreas and the p-duct. It was manufactured using two types of silicone with different hardnesses by considering the tissue properties of each part. The pancreas part was made of a hard-silicone material (Dragon Skin-Silicone Elastomer, Smoothon, AB, Canada) and was $200 \mathrm{~mm}$ in total length and designed to contain the p-duct inside. The p-duct part was $2 \mathrm{~mm}$ in diameter and $200 \mathrm{~mm}$ in length, and it was stabilized using a soft-silicone material (Vero Magenta RGD, Stratasys Ltd., CA, USA) (Figure 2b,c). 


\subsection{Preparation of the EPP for Ex Vivo Examination}

This study was approved by the Institutional Animal Care and Use Committee of the Asan Institute for Life Sciences (2017-14-190) and conformed to US National Institutes of Health guidelines for humane handling of laboratory animals. One pig (Yorkshire; weight, $35.5 \mathrm{~kg}$; Orient Bio, Seongnam, Korea) was euthanized after administering anesthesia according to the ethical procedures for pancreas extraction. Anesthesia was induced by intramuscular injection of a mixture of $50 \mathrm{mg} / \mathrm{kg}$ zolazepam, $50 \mathrm{mg} / \mathrm{kg}$ tiletamine (Zoletil 50; Virbac, Carros, France), and $10 \mathrm{mg} / \mathrm{kg}$ xylazine (Rompun; Bayer HealthCare, Leverkusen, Germany). Next, the pig was immediately euthanized by administering $75-150 \mathrm{mg} / \mathrm{kg}$ potassium chloride. The pancreas was surgically explored to evaluate the antimigration effects of the stents.

\subsection{Measuring Device Setup and Measurement of Antimigration Effects}

The measuring device consisted of a 3D-printed (Ultimaker 3; Ultimaker, Utrecht, The Netherland) jig, measuring table, load cell (KTOYO/333FB, Gyeonggido, Korea) with a measuring range of $0.25-500 \mathrm{~g}$, microcontroller (Arduino UNO R3, Arduino AG, Somerville, MA, USA), and suture thread (Vicryl 4-0, Ethicon Inc., Somerville, NJ, USA). A load cell was fixed to the 3D-printed jig, which functioned as a slider on an instrument base. The force measurement of the four samples was evaluated (Figure 3).

(a)

Suture thread
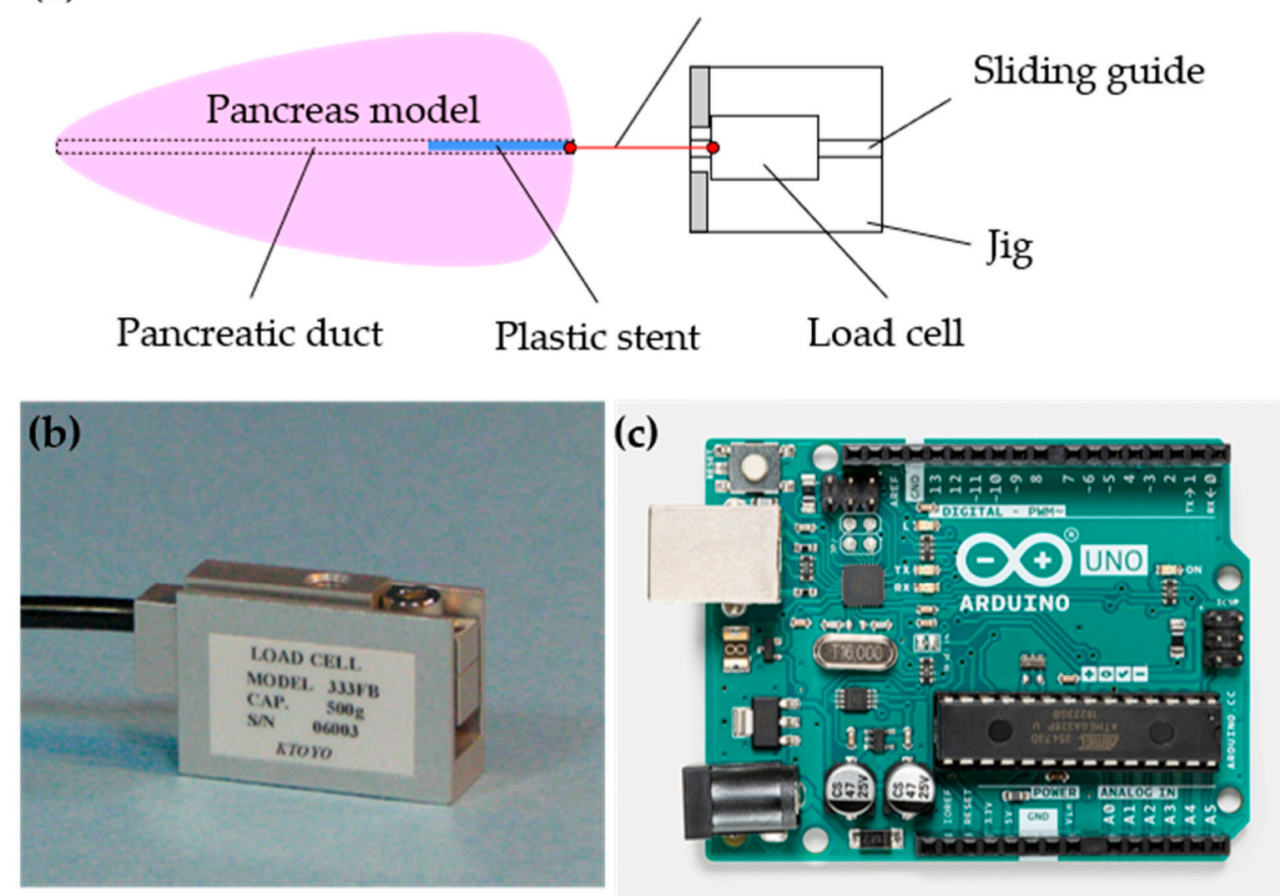

Figure 3. Design of the measuring device for antimigration effects and main components: (a) schematic image of the measuring method, (b) load cell (KTOYO/333FB, Gyeonggi-do, Korea), and (c) microcontroller (Arduino UNO R3, Arduino AG, Somerville, MA, USA).

The four PS types were analyzed for antimigration forces (AMFs) in the 3DP and EPP using customized measuring methods and an integrated measuring device (Figure 4). The load cell of the measuring device was connected to the distal end of the PS using a suture thread. Each stent sample was placed into the p-duct of the 3DP or EPP under fluoroscopic guidance to confirm the stent position. A load cell unit was pulled at a speed of $5 \mathrm{~mm} / \mathrm{s}$ on a sliding guide to measure the AMF of the PS. The total length of the sliding was $80 \mathrm{~mm}$; therefore, the AMFs were measured for $16 \mathrm{~s}$ to stay on the set speed for each measurement. AMF was defined as the resistance force to migration between the inner surface of the 
p-duct models and the stent. The AMF was continuously monitored and realized by using a microcontroller connected to the load cell. A data processing code was developed in a numerical computing environment (Matlab 2018b, MathWorks Inc., Natick, MA, USA). All experiments were repeated 10 times using each PS type.

(a)

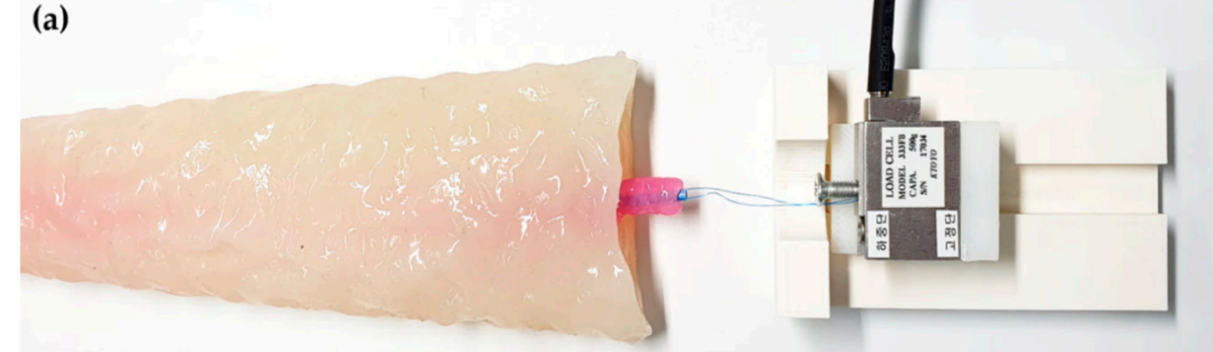

3D printed pancreas with pancreatic duct

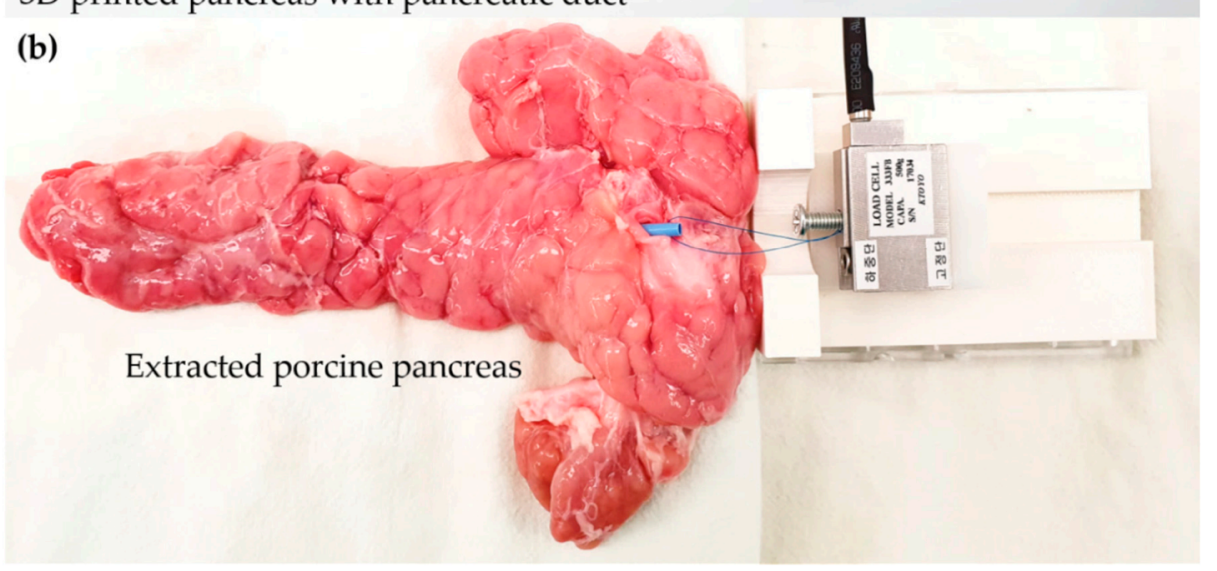

Figure 4. The customized measuring method and the integrated measuring device in (a) the 3Dprinted pancreatic phantom with the pancreatic duct and $(\mathbf{b})$ the extracted porcine pancreas.

\subsection{Histological Examination}

The EPP was transversely sectioned at the proximal, middle, and distal regions of the stented p-duct and the normal region of p-duct to evaluate the possible mucosal injuries during the stent removal procedure. Tissue samples were fixed in $10 \%$ neutral buffered formalin for $24 \mathrm{~h}$ and then embedded in paraffin. The slides were stained with hematoxylin and eosin (H\&E).

\subsection{Statistical Analysis}

Data are expressed as the mean \pm standard deviation. The differences between the stent types were analyzed using the Kruskal-Wallis test or Mann-Whitney U-test, as appropriate. $p$-values $<0.05$ were considered statistically significant. For $p$-values $<0.05$, a Bonferroni-corrected Mann-Whitney U-test was performed to detect which stent type's cause differences ( $p<0.008$ as statistically significant). Statistical analyses were performed using Statistical Package for the Social Sciences (version 24.0; IBM Corp., Armonk, NY, USA).

\section{Results}

All PSs were successfully placed without difficulty at the base of the 3DP and EPP. The AMFs were successfully analyzed without disconnecting any suture thread during the experiments. During the measurement of the AMFs, perforations or scratched traces in the p-duct of the EPP were not detected after complete removal of all PSs.

The maximum AMF (MAMF) values are summarized in Table 2. The mean MAMF was significantly different between the four types $(p<0.001)$ in the 3DP and EPP. In the 3DP, the mean MAMFs in types 2, 3, and 4 were significantly higher than that in type 1 
(all $p<0.001$ ). Furthermore, the mean MAMFs in types 3 and 4 were significantly higher than that in type 2 (all $p<0.001$ ). In the EPP, the mean MAMFs in types 2,3 , and 4 were significantly higher than that in type 1 (all $p<0.001$ ). The mean MAMFs in types 3 and 4 were also significantly higher than that in type 2 (all $p<0.001)$. However, no statistically significant difference was found between types 3 and 4 in the 3DP and EPP $(p=0.113$ and 0.493 , respectively).

Table 2. The maximum antimigration force (MAMF) values in the 3D-printed pancreatic phantom with the pancreatic duct and the extracted porcine pancreas.

\begin{tabular}{|c|c|c|c|c|c|c|c|c|c|c|c|}
\hline \multicolumn{12}{|c|}{ 3D-Printed Pancreatic Phantom with the Pancreatic Duct } \\
\hline \multicolumn{5}{|c|}{ MAMF (N) } & \multicolumn{7}{|c|}{$p$-Value } \\
\hline Number & Type 1 & Type 2 & Type 3 & Type 4 & All * & 1 vs. $2^{\dagger}$ & 1 vs. $3^{+}$ & 1 vs. $4^{\dagger}$ & 2 vs. $3^{+}$ & 2 vs. $4^{+}$ & 3 vs. $4^{+}$ \\
\hline 1 & 0.08 & 0.69 & 2.00 & 1.98 & \multirow{12}{*}{$<0.001$} & \multirow{12}{*}{$<0.001$} & \multirow{12}{*}{$<0.001$} & \multirow{12}{*}{$<0.001$} & \multirow{12}{*}{$<0.001$} & \multirow{12}{*}{$<0.001$} & \multirow{12}{*}{0.113} \\
\hline 2 & 0.10 & 0.70 & 2.00 & 1.94 & & & & & & & \\
\hline 3 & 0.08 & 0.61 & 1.95 & 2.00 & & & & & & & \\
\hline 4 & 0.07 & 0.66 & 1.88 & 1.94 & & & & & & & \\
\hline 5 & 0.09 & 0.69 & 1.98 & 1.89 & & & & & & & \\
\hline 6 & 0.11 & 0.73 & 2.10 & 1.79 & & & & & & & \\
\hline 7 & 0.08 & 0.75 & 2.00 & 1.82 & & & & & & & \\
\hline 8 & 0.09 & 0.66 & 1.89 & 1.91 & & & & & & & \\
\hline 9 & 0.09 & 0.65 & 1.98 & 2.00 & & & & & & & \\
\hline 10 & 0.08 & 0.68 & 1.89 & 1.88 & & & & & & & \\
\hline Mean & 0.09 & 0.68 & 1.97 & 1.92 & & & & & & & \\
\hline SD & 0.01 & 0.04 & 0.07 & 0.07 & & & & & & & \\
\hline
\end{tabular}

Extracted Porcine Pancreas

\begin{tabular}{|c|c|c|c|c|c|c|c|c|c|c|c|}
\hline \multicolumn{5}{|c|}{ MAMF (N) } & \multicolumn{7}{|c|}{$p$-Value } \\
\hline Number & Type 1 & Type 2 & Type 3 & Type 4 & All * & 1 vs. $2^{+}$ & 1 vs. $3^{+}$ & 1 vs. $4^{+}$ & 2 vs. $3^{+}$ & 2 vs. $4^{+}$ & 3 vs. $4^{+}$ \\
\hline 1 & 0.06 & 0.54 & 1.80 & 1.78 & \multirow{12}{*}{$<0.001$} & \multirow{12}{*}{$<0.001$} & \multirow{12}{*}{$<0.001$} & \multirow{12}{*}{$<0.001$} & \multirow{12}{*}{$<0.001$} & \multirow{12}{*}{$<0.001$} & \multirow{12}{*}{0.493} \\
\hline 2 & 0.05 & 0.48 & 1.74 & 1.86 & & & & & & & \\
\hline 3 & 0.06 & 0.52 & 1.69 & 1.83 & & & & & & & \\
\hline 4 & 0.05 & 0.49 & 1.7 & 1.73 & & & & & & & \\
\hline 5 & 0.04 & 0.59 & 1.75 & 1.64 & & & & & & & \\
\hline 6 & 0.07 & 0.44 & 1.72 & 1.69 & & & & & & & \\
\hline 7 & 0.05 & 0.51 & 1.82 & 1.63 & & & & & & & \\
\hline 8 & 0.06 & 0.52 & 1.64 & 1.62 & & & & & & & \\
\hline 9 & 0.07 & 0.43 & 1.71 & 1.69 & & & & & & & \\
\hline 10 & 0.08 & 0.42 & 1.84 & 1.71 & & & & & & & \\
\hline Mean & 0.06 & 0.49 & 1.74 & 1.72 & & & & & & & \\
\hline SD & 0.01 & 0.05 & 0.06 & 0.08 & & & & & & & \\
\hline$p$-value ${ }^{£}$ & $<0.001$ & $<0.001$ & $<0.001$ & $<0.001$ & & & & & & & \\
\hline
\end{tabular}

SD, standard deviation; MAMF, maximum antimigration force. ${ }^{*}$ Kruskal-Wallis, + Compare between the types using the Bonferronicorrected Mann-Whitney U-test. ${ }^{£}$ Compare between the 3D-printed pancreatic phantom and the extracted porcine pancreas using the Bonferroni-corrected Mann-Whitney U-test.

The mean MAMFs of all types of PS in the 3DP were significantly higher than those in the EPP (all $p<0.001)$.

The continuous AMF changes are shown in Figure 5. When the flaps were removed from the p-duct, the AMF rapidly decreased. AMF changes were affected by each location of attached flaps on the surface of the PS in types 3 and 4. 
3D printed pancreatic phantom with pancreatic duct

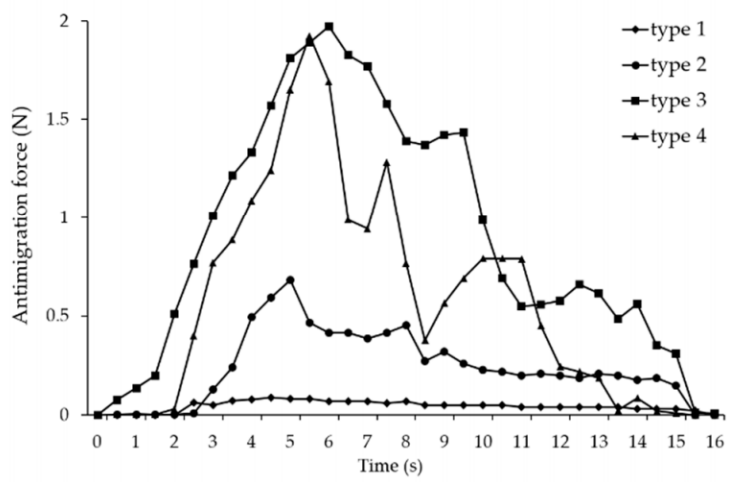

Extracted porcine pancreas

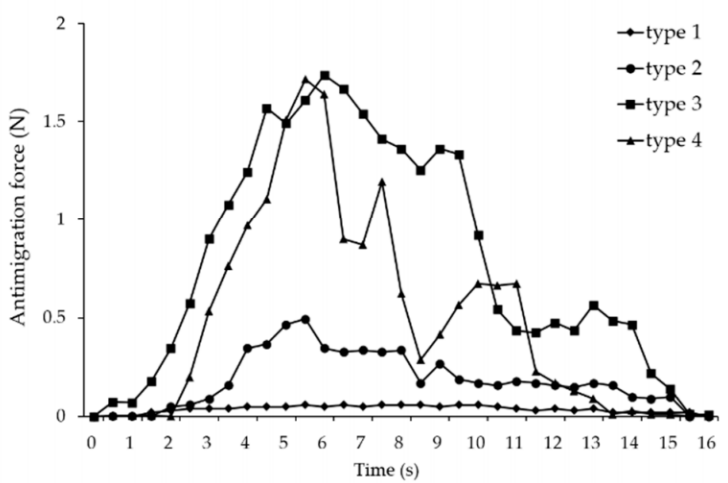

Figure 5. Continuous antimigration force (AMF) changes according to the times in the 3D-printed pancreatic phantom with the pancreatic duct and the extracted porcine pancreas.

In the histological results, no mucosal or submucosal injuries were observed in the proximal, middle, and distal regions of the stented p-duct in types 1,2,3, and 4 compared with the normal p-duct (Figure 6). In addition, perforations or scratched traces of the $\mathrm{p}$-duct were not detected during removal of the PS with all types on gross examination.
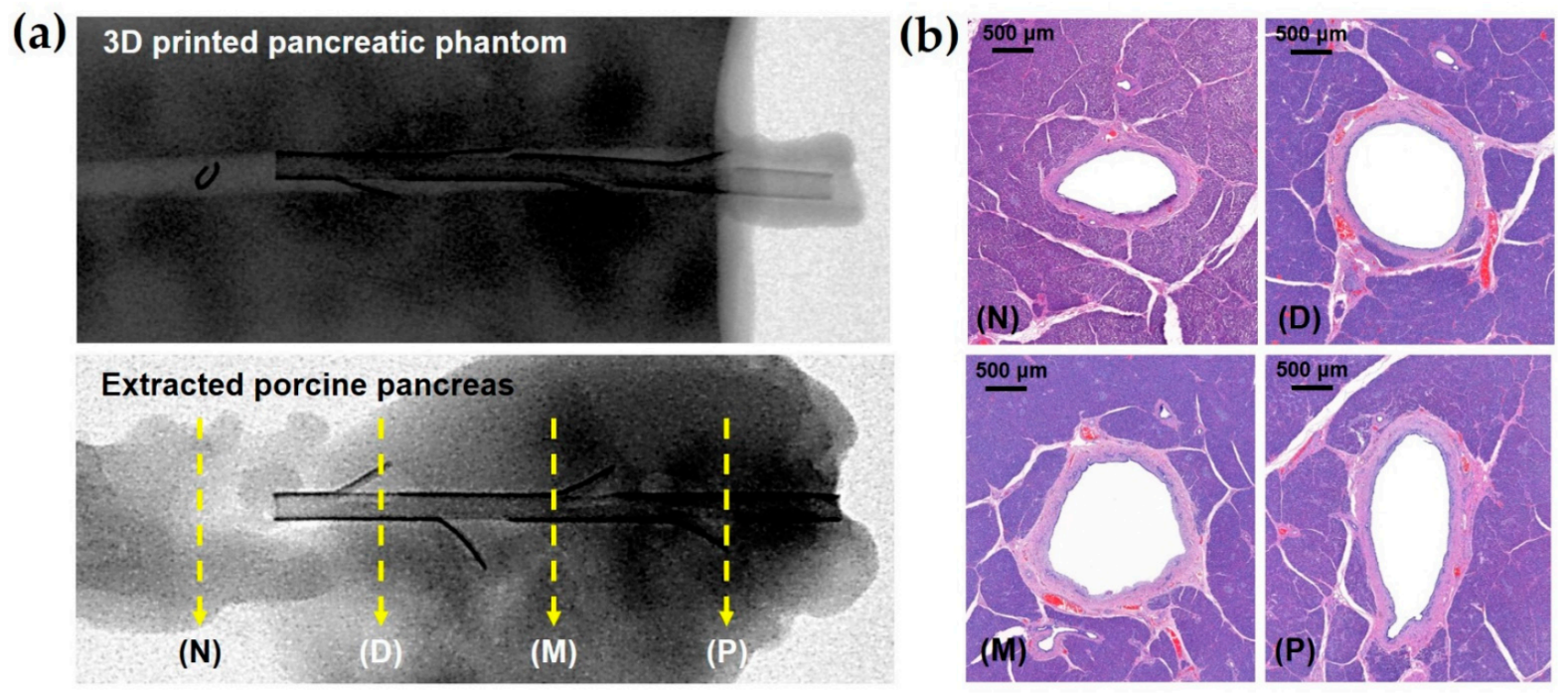

Figure 6. (a) Representative fluoroscopic images in type 3 obtained during the experiment in the 3D-printed pancreatic phantom and the extracted porcine pancreas and locations of tissue sampled for histologic examination where stent was present in proximal (P), middle (M), distal (D), and normal pancreatic duct without stent (N) portions. (b) Representative microscopic images (hematoxylin-eosin staining, magnification $\mathrm{X} 2$ ) in type 3 show no mucosal injuries in the stented p-duct $(\mathrm{P}, \mathrm{M}$, and $\mathrm{D})$.

\section{Discussion}

Our results demonstrated that the resistance to migration of types 2, 3, and 4 was significantly greater than to that of type 1 . Similar results were observed when comparing PSs with four flaps (types 3 and 4) with those with two flaps (type 2). No difference was found between PSs with the same number of flaps (types 3 and 4). These findings support that the AMF proportionally increased as the number of flaps increased, and the vertical and horizontal directions of the flaps did not affect the MAMF. However, the attachment position of the flaps can affect the AMF. Our histological results demonstrated that there were no mucosal injuries caused by attached flaps during stent removal. Stent migration can be sufficiently prevented when the number of flaps is increased, and using a PS with flaps angled $60^{\circ}$ toward the papilla is an effective and safe strategy for preventing stent 
migration. When developing an antimigration stent, the attachment location and number of flaps should be considered.

The endoscopic placement of a PS in the p-duct can resolve or improve symptoms in patients with ductal stricture [12,13]. Despite the several advantages of PS placement, periodic stent exchanges or re-interventional procedures are inevitable because of stent deterioration or obstruction and various other stent-related complications [14-19]. Stentrelated complications included proximal or distal migration, stent occlusion, and stentinduced p-duct changes. In addition, $5.2 \%$ of cases had proximal migration, and $7.5 \%$ had distal migration [9]. To overcome stent migration, PSs were developed in varying shapes and sizes and having varying numbers of flaps, barbs, or flanges. Depending on PS type, stent size usually ranges from 3 to 10 French, with variable numbers of internal and/or external flaps made of polyethylene [20].

The experimental results were properly acquired using the proposed device. Due to the compactness of the device that contains a small number of components with a small footprint, the 3DP and EPP experiments were accomplished in a simple manner. From the acquired data in Table 2, the MAMF in the EPP shows a significantly small value compared with that in the 3DP. This was derived from the frictional effect and elongation ratio of the test pieces. The silicone surrounding the p-duct may provide a small elongation ratio compared with that in the EPP. In contrast, the friction coefficient of the silicone can be higher than that of the p-duct tissues. These are considered major factors that made differences. Nevertheless, the overall tendency was similar in both experiments.

This study has some limitations. First, the total number of PSs was relatively small for performing a robust statistical analysis, even though the Bonferroni-corrected MannWhitney U test was used in this study. Second, the EPP was too tenacious to faithfully reflect the characteristics (e.g., size, configuration, and quality) of the human pancreas. In vivo tests are required to precisely measure the AMF of the PS with flaps in the p-duct. Third, the push-pull gauge apparatus for measuring the AMF was operated at a fixed rate without a delicate control. Fourth, the displacement from the origin point was not clearly defined because the device does not contain any position sensors for the moving axis, which means that the migration distance was not strictly synchronized in each trial. To complement this limitation, the stent location in the 3DP and EPP was confirmed using fluoroscopic guidance. Fifth, the stents were not placed in models representing p-duct stricture but in those representing a normal pancreas without strictures. An ideal stent should be safe and effective in clinical trials. Flaps attached to a stent might effectively prevent migration without mucosal damage of the p-duct. In this study, neither PSs with flaps nor those without flaps caused mucosal damage, such as ductal perforation or scratches during stent removal in the EPP. However, further studies involving in vivo animal models are required for accurate evaluation.

\section{Conclusions}

In conclusion, to our knowledge, this is the first study evaluating the antimigration effects of four PS types in the 3PD and EPP. As the number of flaps increased, the antimigration effects significantly and proportionally increased in the 3DP and EPP. However, the direction of the flaps did not affect the MAMF. The attachment position of the flaps on the surface of the stent also affected the AMF. Additional studies are required to optimize the attachment position and size of the flaps on a PS. The number and location of flaps should be considered when developing a PS for preventing stent migration in clinical settings.

Author Contributions: Conceptualization, S.-C.K. and J.-H.P.; data curation, D.-S.R., J.-M.C., W.-J.K. and J.-H.P.; formal analysis, D.-S.R., J.-M.C., W.-J.K., P.-H.K. and J.-H.P.; funding acquisition, S.-C.K. and J.-H.P.; investigation, D.-S.R., J.-M.C., W.-J.K. and J.-H.P.; methodology, D.-S.R., J.-M.C. and J.-H.P.; project administration, D.-S.R., J.-M.C. and J.-H.P.; resources, J.-M.K., K.-B.L., Y.-B.P., D.-S.W., J.-W.K. and S.-H.K.; software, J.-M.C.; supervision, J.-H.P. and S.-C.K.; validation, J.-M.K., K.-B.L. and Y.-B.P.; visualization, D.-S.W., J.-W.K. and S.-H.K.; writing-original draft preparation, D.-S.R., J.-M.C., W.-J.K. and J.-H.P.; writing-review and editing, D.-S.R., J.-M.C., W.-J.K., J.-M.K., K.-B.L., 
Y.-B.P., D.-S.W., J.-W.K., S.-H.K., P.-H.K., S.-C.K. and J.-H.P. All authors have read and agreed to the published version of the manuscript.

Funding: This research was partially funded by the KITECH R\&D program (JB210003) and was supported by Korea Medical Device Development Fund grand funded by the Korea government (the Ministry of Science and ICT, the Ministry of Trade, Industry and Energy, the Ministry of Health \& Welfare, Republic of Korea, the Ministry of Food and Drug Safety) (Project Number: 202011D16).

Institutional Review Board Statement: This study was approved by the Institutional Animal Care and Use Committee of Asan Institute for Life Sciences (2017-14-190) and conformed to US National Institutes of Health guidelines for humane handling of laboratory animals.

Informed Consent Statement: Not applicable.

Data Availability Statement: The data presented in this study are available on request from the corresponding author. The data are not publicly available due to ethical issues.

Conflicts of Interest: The authors declare no conflict of interest. The funders had no role in the design of the study; in the collection, analyses, or interpretation of data; in the writing of the manuscript, or in the decision to publish the results.

\section{References}

1. Costamagna, G.; Mutignani, M. Pancreatic stenting for malignant ductal obstruction. Dig. Liver Dis. 2004, 36, 635-638. [CrossRef] [PubMed]

2. Devier, J.; Delhaye, M.; Cremer, M. Pancreatic duct stones management. Gastrointest. Endosc. Clin. N. Am. 1998, 8, 163-179.

3. Binmoeller, K.F.; Jue, P.; Seifert, H.; Nam, W.C.; Izbicki, J.; Soehendra, N. Endoscopic pancreatic stent drainage in chronic pancreatitis and a dominant stricture: Long-term results. Endoscopy 1995, 27, 638-644. [CrossRef] [PubMed]

4. Tringali, A.; Boskoski, I.; Costamagna, G. The role of endoscopy in the therapy of chronic pancreatitis. Best Pract. Res. Clin. Gastroenterol. 2008, 22, 145-165. [CrossRef] [PubMed]

5. Freeman, M.L.; Guda, N.M. Prevention of post-ERCP pancreatitis: A comprehensive review. Gastrointest. Endosc. 2004, 59, 845-864. [CrossRef]

6. Sofuni, A.; Maguchi, H.; Itoi, T.; Katanuma, A.; Hisai, H.; Niido, T.; Toyota, M.; Fujii, T.; Harada, Y.; Takada, T. Prophylaxis of post-endoscopic retrograde cholangiopancreatography pancreatitis by an endoscopic pancreatic spontaneous dislodgement stent. Clin. Gastroenterol. Hepatol. 2007, 5, 1339-1346. [CrossRef] [PubMed]

7. Sofuni, A.; Maguchi, H.; Mukai, T.; Kawakami, H.; Irisawa, A.; Kubota, K.; Okaniwa, S.; Kikuyama, M.; Kutsumi, H.; Hanada, K.; et al. Endoscopic pancreatic duct stents reduce the incidence of post-endoscopic retrograde cholangiopancreatography pancreatitis in high-risk patients. Clin. Gastroenterol. Hepatol. 2011, 9, 851-858. [CrossRef] [PubMed]

8. Bakheet, N.G.; Park, J.H.; Shin, S.H.; Hong, S.R.; Park, Y.J.; Shim, I.K.; Hwang, C.M.; Jeon, J.Y.; Lopera, J.E.; Song, H.Y.; et al. A Novel Biodegradable Tubular Stent Prevents Pancreaticojejunal Anastomotic Stricture. Sci. Rep. 2020, $10,1518$. [CrossRef] [PubMed]

9. Johanson, J.F.; Schmaltz, M.J.; Geenen, J.E. Incidence and risk factors for biliary and pancreatic stent migration. Gastrointest. Endosc. 1992, 38, 341-346. [CrossRef]

10. Rana, S.S.; Sharma, R.; Gupta, R. Endoscopic retrieval of two proximally migrated plastic pancreatic duct stents. JGH Open 2019, 12, 97-98. [CrossRef] [PubMed]

11. Kawaguchi, Y.; Lin, J.C.; Kawashima, Y.; Maruno, A.; Ito, H.; Ogawa, M.; Mine, T. Risk factors for migration, fracture, and dislocation of pancreatic stents. Gastroenterol Res. Pract. 2015, 2015, 365457. [CrossRef] [PubMed]

12. Fuji, T.; Amano, H.; Harima, K.; Aibe, T.; Asagami, F.; Kinukawa, K.; Ariyama, S.; Takemoto, T. Pancreatic sphincterotomy and pancreatic endoprosthesis. Endoscopy 1985, 17, 69-72. [CrossRef] [PubMed]

13. Cremer, M.; Deviere, J.; Delhaye, M.; Baize, M.; Vandermeeren, A. Stenting in severe chronic pancreatitis: Results of medium-term follow-up in seventy-six patients. Endoscopy 1991, 23, 171-176. [CrossRef] [PubMed]

14. Deveiere, J. Pancreatic stents. Gastrointest. Endosc. Clin. N. Am. 2011, 21, 499-510. [CrossRef] [PubMed]

15. Nguyen-Tang, T.; Dumonceau, J.M. Endoscopic treatment in chronic pancreatitis, timing, duration, and type of intervention. Best Pract. Res. Clin. Gastroenterol. 2010, 24, 281-298. [CrossRef] [PubMed]

16. Vitale, G.C.; Cothron, K.; Vitale, E.A.; Rangnekar, N.; Zavaleta, C.M.; Larson, G.M.; Binford, J.; Hammond, B. Role of pancreatic duct stenting in the treatment of chronic pancreatitis. Surg. Endosc. 2004, 18, 1431-1434. [CrossRef] [PubMed]

17. Weber, A.; Schneider, J.; Neu, B.; Meining, A.; Born, P.; Schmid, R.M.; Prinz, C. Endoscopic stent therapy for patients with chronic pancreatitis: Results from a prospective follow-up study. Pancreas 2007, 34, 287-294. [CrossRef] [PubMed]

18. Eleftheradis, N.; Dinu, F.; Delhaye, M.; le Moine, O.; Baize, M.; Vandermeeren, A.; Hookey, L.; Devière, J. Long term outcome after pancreatic stenting in severe chronic pancreatitis. Endoscopy 2005, 37, 223-230. [CrossRef] [PubMed] 
19. Deviere, J.; Bell, R.H.; Berger, H.G.; Traverso, L.W. Treatment of chronic pancreatitis with endotherapy or surgery: Critical review of randomized control trials. J. Gastrointest. Surg. 2008, 12, 640-644. [CrossRef] [PubMed]

20. Somogyi, L.; Chuttani, R.; Croffie, J.; DiSario, J.; Liu, J.; Mishkin, D.S.; Shah, R.; Tierney, W.; Wong Kee Song, L.M.; Petersen, B.T. Biliary and pancreatic stents. Gastrointest. Endosc. 2006, 63, 910-919. [CrossRef] [PubMed] 